\title{
«LO QUATORZEN CAPITOL». INTERVENCION REGIA Y FRAUDE ELECTORAL EN EL PATRICIADO URBANO DE UNA CIUDAD VALENCIANA. ORIHUELA, 1458-1479
}

\author{
Miguel-Ángel González Hernández \\ Universidad de Alicante/Universitat d'Alacant
}

\section{RESUMEN}

Este trabajo aborda una primera cuestión dedicada a la legislación contenida en los privilegios dados a Orihuela por Juan II de Aragón en abril de 1459 para la reimplantación del sistema de insaculación y las variadas reinterpretaciones que hacía el patriciado local de esa legislación durante el período de los años 1458 y 1479. Esta legislación política y administrativa debía de servir como mediación de la monarquía frente a las luchas de poder de las distintas facciones del patriciado urbano. Y la segunda cuestión presenta el fraude electoral en sus diversas formas, ya sea en las recusaciones contra candidatos electos, las modalidades utilizadas y especialmente, durante la selección y aceptación previa de candidatos en el sistema de graduación para formar las bolsas de caballeros y ciudadanos. Este sistema estaba diseñado en el privilegio de abril de 1459 y aún así, los fraudes electorales se siguieron produciendo. Esta situación reflejaba la tensión política vivida en una ciudad valenciana meridional en la segunda mitad del siglo XV y se enmarcaba en un contexto mayor que reflejaba ese mismo proceso de enfrentamiento urbano de otras ciudades medievales del ámbito del reino de Valencia dentro de la Corona de Aragón.

Palabras clave: Juan II de Aragón, reino de Valencia, Orihuela, intervención regia, insaculación, patriciado urbano, fraude electoral y graduación. 


\begin{abstract}
This paper addresses the first issue devoted to the legislation contained in the privileges given to Orihuela by John II of Aragon in April 1459 for the reintroduction of the balloting system and the various reinterpretations that made the local gentry of this legislation during the years 1458 and 1479. This legislation and administrative policy was to serve as a mediation of the monarchy to the power struggles of various factions of the urban gentry. And second question is presented electoral fraud in its various forms, whether in legal challenges against candidates elected, the methods used and particularly during the pre-selection and acceptance of candidates in the ranking system to form pockets of men and citizens. This system was designed in the privilege of April 1459 and yet the electoral fraud continued to produce. This reflected the political tensions lived in a town south of Valencia in the second half of the fifteenth century and was part of a larger context, reflecting the same process of coping with urban area of the medieval cities of the kingdom of Valencia in the Crown of Aragon.
\end{abstract}

Keywords: John II of Aragon, the kingdom of Valencia, Orihuela, royal intervention, balloting, urban patricians, electoral fraud and graduation.

\title{
1. ORIHUELA. UNA CIUDAD VALENCIANA DE REALENGO EN PUGNA CON JUAN II DE ARAGÓN.
}

Este trabajo se centra en el estudio de un ámbito urbano (Orihuela) desde el punto de vista político (instituciones-el consell) y el poder de su jurisdicción y competencias supervisados por la Monarquía. En un contexto más amplio se puede enmarcar dentro del estudio de la ciudad medieval y de las relaciones de las sociedades o comunidades urbanas, no sólo en una ciudad del reino de Valencia dentro de la Corona de Aragón sino en un contexto más amplio sobre las ciudades medievales de la Baja Edad Media ${ }^{1}$. Un periodo cronológico situado sobre el estudio de la ciudad de Orihuela inserto entre los trabajos de la primera

1 La reciente obra de FERRERO MICÓ y GUÍA (2008) presenta una recopilación sobre investigaciones dedicadas al análisis de las instituciones políticas que sustentaban el poder la monarquía en la Corona de Aragón en la Baja Edad Media. Véase, FERRERO MICÓ, R. y GUíA, Ll. (eds.), Corts i Parlaments de la Corona d'Aragó. Unes institucions emblemátiques en una monarquia medieval. Valencia, 2008. En un contexto político superior, véase, Actas del XV Congreso de Historia de la Corona de Aragón, El poder real en la Corona de Aragón siglos XIVXV, (Jaca, 20-25 septiembre, 1993). Zaragoza, 1996. HEERS, J., Los partidos y la vida política en el Occidente medieval. Buenos Aires, 1986. BARRIO BARRIO, J.A. (ed.), Los cimientos del Estado. Chancillerías, notariado y privilegios reales en la construcción del Estado en la Edad Media. Alicante, 2004. 
mitad del siglo XV realizados por Barrio Barrio², la continuación de la tesis doctoral de Ponsoda López de Atalaya y completados por Bernabé Gil ${ }^{3}$ durante la Edad Moderna. La cronología estudiada ha sido desde julio del año 1458 hasta enero del año 1479 (reinado de Juan de II de Aragón).

En el régimen municipal medieval el profesor Barrio Barrio ${ }^{4}$ estableció la distinción entre los oficios con competencias políticas (justicia, jurados, almotacén y sobrecequiero), los oficios con competencias económicas (clavario, obrer de mur e valls, fabriquero, munidor ${ }^{5}$, comptadors, oficial del almudí, tablajero, acequieros y el del peso de los florines y de la bolla), los oficios de administración (el escribano y los abogados), los oficios de representación de la ciudad (mensajeros y síndicos en Cortes) y los oficios menores de servicio (el corredor público, el alfaqueque, el encargado del reloj, el trompeta, el tambor, el alguacil, el carcelero y el verdugo -morro de vaques-).

Los oficios políticos y económicos se elegían anualmente ${ }^{6}$ y su número era: el justicia criminal (uno), su lugarteniente (uno), el justicia civil (uno), su asesor (uno), los conselleres (cuarenta), obrer de mur e valls (uno), monidor (uno), clavario (uno) y contadores (cinco). En la llamada vigilia de Pascua de Pentecostés, en torno a mayo de cada año, eran elegidos los oficios de jurats (cinco) y sobrecequier (uno). Y el 29 de septiembre en la fiesta de san Miguel Arcángel se elegía el mustasaf (uno). Todo este proceso de extracción de oficios tenía una renovación parcial de personas en las revisiones de las tres principales bolsas de ciudadanos que se realizaba el segundo miércoles de Cuaresma (entre febrero y marzo). El sistema de selección de candidatos idóneos para ser electos se regía por el privilegio de insaculación (años 1445 y 14597) mediante el proceso de graduación. La extracción se hacía de una manera ordinaria en la fecha prevista o extraordinaria

2 BARRIO BARRIO, J.A., Gobierno municipal en Orihuela durante el reinado de Alfonso V 14161458. Alicante, 1995; id., «Una oligarquía fronteriza en el mediodía valenciano: el patriciado de Orihuela. Siglos XIII-XV», Revista d'Història Medieval, 9, Valencia 1998, pp. 105-126.

3 Desde el punto de vista de las instituciones político-administrativas de Orihuela, véase BERNABE GIL, D., Monarquía y patriciado urbano en Orihuela, 1445-1707. Alicante. 1989.

4 BARRIO BARRIO, J.A., Gobierno municipal en Orihuela..., op. cit.

5 El oficio de munidor definido por el profesor Hinojosa como «el providor de alimentos de la villa». HINOJOSA MONTALVO, J.: «El municipio valenciano en la Edad Media: características y evolución», Estudis Baleàrics, 31, Mallorca 1989, pp. 39-59.

6 A mediados del siglo XV se seguía manteniendo que el inicio del año correspondía al 25 de diciembre de cada año, por lo que el cambio de algunos de los principales oficios municipales se realizaba en esa fecha (ese día estaba considerado como el nacimiento de Jesucristo).

7 El del año 1445 era denominado en la documentación como el Privilegi del Sach concebido con una vigencia de ocho años y el de 1459 como el Privilegi del Regiment con una vigencia de cien años. Cfr. BERNABÉ GIL, D., Monarquía y patriciado urbano en Orihuela, 1445-1707. Alicante 1990, p. 30. 
en caso de sucederse una incidencia en el año de mandato de algún oficio local. Los principales oficios de la ciudad estaban sujetos al cumplimiento de unos estrictos requisitos que limitaban el acceso a esos cargos municipales a una élite de los ciudadanos (una minoría).

En el siglo XV la Corona de Aragón ${ }^{8}$ era gobernada bajo el sistema político de la monarquía pero no habría que entenderla como una monarquía autoritaria como en siglos posteriores sino como un sistema que pugnará con los otros poderes políticos territoriales (señoríos) y municipios (ciudades), por imponer un modelo de sistema político uniforme en todo el territorio de su jurisdicción a través de la concesión de la insaculación. A lo largo del siglo XV la monarquía irá extendiendo su intervención política en las ciudades medievales mediante la concesión de privilegios reales ${ }^{9}$, especialmente de interés es el estudio del nuevo sistema de elección de cargos municipales a través del modelo de la insaculación (sac i sort) y que exigirá unos requisitos a los estamentos ciudadanos para poder ejercer alguno de los distintos oficios municipales. Continuamente, tanto en Orihuela como en otras ciudades valencianas, se asistirá a la diferencia de criterio entre el monarca reinante y las ciudades: por las formas de gobernar, las competencias delegadas por la Corona y la defensa de los privilegios antiguos heredados de siglos anteriores. No todos los reinados fueron similares en cuanto a la mayor o menor acentuación de esas pugnas políticas (monarquía y patriciado urbano) pero especialmente el reinado de Alfonso V de Aragón fue clave en

8 Sobre el estudio de las instituciones políticas en la baja Edad Media en la Corona de Aragón, véase, FONT y RIUS, J., «Las instituciones de la Corona de Aragón en la primera mitad del siglo XV (Reinados de Fernando de Antequera y Alfonso el Magnánimo», IV Congreso de Historia de la Corona de Aragón, Mallorca, 1955. TORRAS i RIBÉ, J.Ma ., «El procedimiento insaculatorio en los municipios de la Corona de Aragón, entre la renovación institucional y el sometimiento a la monarquía (1427-1714)», Actas del Congreso sobre Jerónimo Zurita, su época y su escuela, Zaragoza, 1986. BARRIO BARRIO, J.A., «La introducción de la insaculación en el antiguo reino de València, Xàtiva, 1427», I Congrés d'Administració Valenciana: De la Història a la Modernitat, Valencia, 1991. FALCÓN PÉREZ, M.I., Organización municipal de Zaragoza en el siglo XV, Zaragoza, 1978. Id., «Origen y desarrollo del municipio medieval en el reino de Aragón», Estudis Baleàrics, 31, Mallorca 1989, pp. 73-91. BERNABÉ GIL, D., «La administración municipal» en Historia de la Provincia de Alicante, Edad Moderna, Murcia, 1985, IV, pp. 239-268. Id., Monarquía y patriciado urbano en Orihuela, 1445-1707, Alicante, 1989. HINOJOSA MONTALVO, J., «El municipio valenciano en la Edad Media... op. cit., pp. 39-59.

9 BARRIO BARRIO, J.A., CABEZUELO PLIEGO, J.V., «La defensa de los privilegios locales y la resistencia a la centralización política en la gobernación de Orihuela», Anales de la Universidad de Alicante, Historia Medieval, 13, Alicante 2000-2002, pp. 9-42. BARRIO BARRIO, J.A., «Los privilegios reales. Centralización estatal y transmisión de la política real», Los cimientos del Estado. Chancillerías, notariado y privilegios reales en la construcción del Estado en la Edad Media. Alicante, 2004, pp. 119-156. 
la intervención de la monarquía en la administración local y durante el reinado de Juan II se culminará buena parte de la extensión de la nueva legislación que impondrá ese nuevo modelo de acceso a los oficios municipales.

La ciudad de Orihuela ha servido de ejemplo para comprobar la existencia de un pactismo entre los diversos poderes políticos de la época. El continuo intercambio de cartas entre la Corona y la ciudad ha ayudado a definir las diversas competencias delegadas que ostentaba Orihuela así como los intentos por recuperar parte de las antiguas competencias que estaban en manos de la monarquía. Sólo la concesión de las nuevas leyes políticas (privilegios) limitó el antiguo poder de las ciudades, y en este caso de Orihuela, y por tanto en los estamentos privilegiados que las gobernaban. Esa nobleza ciudadana, que basaba su poder económico en la posesión de las tierras circundantes, vio mermada su influencia política en la ciudad, y a su vez, se vio amenazada por las restricciones para el acceso de un cargo político local. Este hecho acentuó aún más el endémico enfrentamiento entre bandos y facciones ciudadanas (bandosidades ${ }^{10}$ ) tan características de la segunda mitad del siglo XV. En Orihuela hubo numerosos cambios de tipo político-administrativo a lo largo del reinado de Alfonso V de Aragón ya estudiados por el profesor Barrio Barrio ${ }^{11}$. Desde el ascenso de Orihuela del rango administrativo de villa al de ciudad en el año 1437 hasta los cambios en los sistemas de extracción y elección de cargos municipales a partir del antiguo sistema de cooptación al nuevo de insaculación del año 1445. Estos cambios pretendían dos iniciativas por parte de la Corona: por un lado, el control del acceso de los cargos municipales a favor de un naciente patriciado urbano afín a las normas y directrices de la monarquía, y por otro lado, frenar las continuas disputas y bandosidades que habían tenido lugar a lo largo del siglo XV en Orihuela en varios bandos enfrentados como los Rocafull y los Rocamora.

\footnotetext{
${ }^{10}$ Las bandosidades eran las luchas armadas entre diversas facciones de linajes de las ciudades medievales así denominadas en el reino de Valencia. Sus luchas estaban motivadas por la pugna continuada por el monopolio del control político, económico y de prestigio social en cada momento histórico. En la ciudad de Orihuela fueron bastante habituales durante el reinado de Juan II de Aragón, llegando a tener que intervenir el propio rey dadas las muertes que se producían y el aumento de la tensión en una ciudad de la frontera meridional de la Corona de Aragón. Sobre este tema, véase en este mismo volumen, PONSODA LÓPEZ DE ATALAYA, S. y SOLER MILLA, J.L., «Violencia nobiliaria en el sur del Reino de Valencia en la Baja Edad Media», Anales de la Universidad de Alicante, Historia Medieval, 16, Alicante 2009-2010.

${ }^{11}$ BARRIO BARRIO, J.A., Gobierno municipal en Orihuela..., op. cit. La nueva situación de político-administrativa configurada durante el reinado de Alfonso V incidiría el cambio del sistema de elección de cargos con un nuevo modelo de organización de los órganos de gobierno locales que ya había sido aplicado por la Corona en otras ciudades valencianas (sirva el ejemplo de Xàtiva del año 1427).
} 
Desde 1458 hasta 1479 se observó un desarrollo continuado del intervencionismo de la monarquía en asuntos municipales con continuas limitaciones a los antiguos privilegios de Orihuela (sirvan como ejemplo las dos provisiones de septiembre y noviembre de 1458$)^{12}$. Este proceso continuó en la segunda mitad del siglo XV con Juan II que siguió interviniendo cada vez más en las decisiones diarias municipales, especialmente en temas judiciales y políticos sobre competencias, es decir, quién debía decidir sobre ciertos asuntos públicos y sobre la presencia de los oficiales reales en las graduaciones (el gobernador general o su lugarteniente). En el de 1445 se señalaba expresamente la exclusión de los oficiales reales (gobernador y baile) de todo el proceso electoral ${ }^{13}$. Luego, pocos años después, la propia ciudad a instancia de parte solicitará la mediación y presencia de dichos oficiales en los actos de graduación y juramento oficial de las magistraturas locales para evitar la perduración de los enfrentamientos ${ }^{14}$. La injerencia de la monarquía en las ciudades estaba representada con la insaculación y en ocasiones, se recurría a su suspensión cautelar para volver a ejercer un dominio sobre las voluntades del patriciado urbano ${ }^{15}$.

Las ordenanzas del año 1445 concedidas por Alfonso V a Orihuela tuvieron también parte de vigencia durante el reinado de su hermano Juan II a pesar de la suspensión cautelar de los años 1450-1456 ${ }^{16}$. El privilegio de abril de 1459 , que volvía a aplicar el sistema de insaculación, mantenía entre sus disposiciones buena parte de los capítulos concedidos por su antecesor. Sí es cierto, que hubo modificaciones a esos capítulos a lo largo de 1458 y 1479, especialmente, fue controvertido el capítulo catorce que imponía los requisitos necesarios para acceder a ser graduado y centro del fraude electoral local.

${ }^{12}$ Estas dos provisiones de 1458 así como la ratificación del privilegio de insaculación de 1459 fueron concedidas a cambio de un servicio de dinero para el monarca. Orihuela tuvo que solicitar un préstamo de censal de 2.000 sólidos para pagar una de las provisiones de 1458. Esta situación de solicitud de dinero para conceder o ratificar privilegios fue común a lo largo de todo reinado y en especial también en la convocatoria de las cortes del reino. Véase, KÜCHLER, W., Les finances de la Corona d'Aragó al segle XV (regnats d'Alfons V i Joan II). Valencia. 1997. SÁNCHEZ ARAGONÉS, L.Ma ., Las Cortes de la Corona de Aragón durante el reinado de Juan II (1458-1479). Monarquía, ciudades y relaciones entre el poder y sus súbditos. Zaragoza, 2004.

${ }^{13}$ BERNABÉ GIL, D., Monarquía y patriciado urbano..., op. cit. p. 31.

${ }^{14}$ Esta situación también fue común en otras ciudades medievales de la Corona de Aragón según estudios de FALCON PEREZ,M.I., «Origen y desarrollo del municipio medieval ..., op. cit., p. 91.

${ }^{15}$ Ibídem, p. 91.

${ }^{16}$ BARRIO BARRIO, J.A., «La intervención real en la ciudad de Orihuela a través de la suspensión de la insaculación en 1450 y su reimplantación en 1459», Pedralbes. Revista d'Història Moderna. Tercer Congrès d'Història Moderna de Catalunya, 13-I, Barcelona, 1993, pp. 401-408 
En el privilegio de abril de 1459 se mantenía el sistema de acceso a las bolsas de ciudadanos mediante la celebración del acto de la graduación (capítulo catorce de las ordenanzas de 1445 que fue reformado en abril de 1459) con la confección de tres bolsas ${ }^{17}$ cuyo ingreso estaba supeditado a la tenencia y mantenimiento de caballo y armas. A su vez, las tres bolsas principales de ciudadanos también se subdividían en tres bolsas más de las mismas características que las anteriores pero sólo destinadas a la elección del numeroso grupo de conselleres (cuarenta en total y veintiuno en asistencia para la legalidad de la convocatoria de un consell). El sistema elegido para elaborar las bolsas de ciudadanos y su contenido se hacía con la confección de redolines cuyo peso, forma y medida debía de ser idéntico para evitar fraudes a la hora de seleccionarlos (capítulo quinto de las ordenanzas de 1445). Por su parte, D. Bernabé Gil ${ }^{18}$ realizó un estudio comparativo entre ambos privilegios (años 1445 y 1459) que ponía de manifiesto la vigencia de unos capítulos como base fundamental de todo el sistema electoral empleado en Orihuela durante la segunda mitad del siglo XV y englobando el final del reinado de Alfonso V y todo el reinado de Juan II de Aragón.

La existencia de dos cajas que contenían estas bolsas, es decir, una caja pequeña inserta en una más grande con tres cerraduras cada una de ellas, y sus llaves, custodiadas por distintos oficios municipales para evitar que no pudieran ser abiertas sino era siguiendo el protocolo oficial contenido en los privilegios ${ }^{19}$. También se mantuvo la alternancia en los oficios por turno anual entre los caballeros y los ciudadanos mayores para ser elegidos como justicia criminal o civil. En los jurados se estableció que los caballeros contaran con dos miembros y los ciudadanos mayores con tres. Y finalmente, en los conselleres el reparto fue de dieciséis componentes para los caballeros y los ciudadanos mayores, y ocho miembros para los ciudadanos menores ${ }^{20}$. De esta manera, la representatividad ${ }^{21}$ en el consell de los cuarenta y siete miembros (justicias, jurados y conselleres)

${ }^{17}$ En la práctica había en realidad seis bolsas de ciudadanos contando las de los conselleres: bolsa de los conselleres de caballeros y hòmens de paratge, bolsa de conselleres de ciutadans de má maior y bolsa de conselleres de ciutadans de má menor.

${ }^{18}$ BERNABE GIL, D., Monarquía y patriciado urbano..., op. cit. pp. 29-53.

${ }^{19}$ Este protocolo de custodia de las cajas procedía de Alfonso V de Aragón, véase BARRIO BARRIO, J.A., Gobierno municipal en Orihuela..., op. cit. p. 215. Durante el reinado de Juan II se mantendrá vigente.

20 BARRIO BARRIO, J.A., Gobierno municipal en Orihuela..., op. cit. p. 216.

${ }^{21}$ En el período estudiado es poco frecuente que junto al nombre aparezca la profesión del candidato por lo que es difícil precisar la procedencia social de sus miembros sólo atendiendo a la bolsa donde estaban incluidos. En el conjunto de profesiones del artesanado destacan los perayres como los que formaban el grupo más numeroso. En esta dirección de investigación social se enmarca el trabajo de NARBONA VízCAINO, R., «Orígenes sociales de los tres estamentos ciudadanos en Valencia medieval», Estudis, 16, Valencia 1990, pp. 7-30. 
quedaban dos tercios para los ciudadanos (veintiocho miembros) y un tercio para los caballeros (once miembros). En cuanto a las modificaciones introducidas por Juan II de Aragón en el privilegio de 1459 destacan, sobre todo, el número de oficiales electos para formar no sólo el consell de gobierno sino incluso los cargos de gestión. Los jurados pasaron de ser tres a cinco miembros. Los contadores de dos a cinco miembros.

El mayor ejemplo del control monárquico sobre las competencias municipales se observaba cada año en los procesos de selección de candidatos para ocupar un oficio municipal a través del proceso selectivo de la graduación. Este proceso de control tenía su culminación en la extracción y elección de cargos. En las bolsas de ciudadanos que se formaban con cada graduación se apreciaba una limitación de los ciudadanos de los estamentos que formaban estas bolsas. El control era cada año más estricto y se fue configurando un patriciado urbano formado por familias asociadas en facciones. Este hecho se comprueba en las continuas denuncias que realizaban y quedaban registradas en los propios consells en los días de las extracciones de los oficios. Numerosos ciudadanos, aún siendo electos, no eran admitidos para ocupar el oficio designado en base a las habituales denuncias de otros miembros del consell local. Esta situación se inició en el mismo año de reimplantación del sistema de insaculación dado por Juan II y continuó acentuándose en los siguientes años de 1460 y 1461 para volver a repetirse en lo largo de esa década y otra vez en $1474^{22}$. Esa legislación teórica tenía cada año sus fraudes y denuncias. Su difícil aplicación se debía a que cada facción ciudadana trataba de ocupar mayores cuotas de poder municipal. Finalmente, los grupos familiares (linajes) fueron cerrando el círculo del monopolio de las bolsas de ciudadanos. Los oficiales del rey en la ciudad y el propio rey supervisarán y alterarán las decisiones municipales haciendo imprescindible que se les consulte en numerosos asuntos locales. Con ello, muchos de los antiguos privilegios medievales de Orihuela irán quedando atrás en el tiempo y un nuevo modelo políticoadministrativo se irá definiendo en la ciudad durante el reinado de Juan II de Aragón.

${ }^{22}$ La falta de documentación continuada no permite conocer de una manera exhaustiva todo este complejo desarrollo del control de la monarquía sobre las competencias municipales. En la década de los años 70 también la falta de documentación sólo permitir dar una visión aproximada de la continuación de ese estrechamiento de las competencias municipales en beneficio de la intervención de os oficiales reales destinados en Orihuela así como del propio rey a través del intercambio de cartas con la ciudad. En este punto se enmarcan el medio centenar de cartas enviadas por Orihuela a Juan II para mediar, arbitrar, designar y sentenciar tanto procesos judiciales como solicitar interpretaciones correctas de los privilegios dados por él mismo en abril de 1459. 
La graduación o habilitación de candidatos se celebraba durante los primeros días de la fiesta de la Cuaresma. En días previos, los aspirantes a pertenecer a alguna de las bolsas de ciudadanos o a promocionarse de la bolsa menor a la mayor (bolsa de ciudadanos menores y bolsas de ciudadanos mayores), comunicaban sus nombres al justicia criminal o a los jurados. El mecanismo de inclusión o promoción se realizaba mediante una votación secreta en la que participaban los cuarenta conselleres miembros del consell que utilizaban unas simples habas blancas y habas negras. Para ser admitido era necesario obtener la mitad más una de las habas blancas de los votos emitidos por los miembros del consell. Si esta situación no se producía el aspirante no obtenía su objetivo. Dichas habas eran introducidas en una bolsa que colgaba de la pared del consell y que se descolgaba para hacer el recuento ${ }^{23}$.

Muchas de las noticias sobre las interioridades sobre los problemas de Orihuela durante los años de reinado de Juan II de Aragón aparecían descritos en las decenas de $\operatorname{cartas}^{24}$ examinadas y que se conservan dentro de las actas de consell. La administración del territorio de la monarquía en el área valenciana estaba supeditada a la Gobernación General de Orihuela donde residía el gobernador y su lugarteniente. Las cuestiones de los derechos reales estaban a cargo de la Bailía General dellá Sexona a cargo de un baile general que residía también en Orihuela. Los enfrentamientos con estos delegados de la monarquía en Orihuela denotaban ese cambio en el rumbo de la política centralista de los monarcas bajomedievales tendente a intervenir en la mayor parte de las cuestiones cruciales de la organización ciudadana y limitar al máximo la autonomía de la ciudad medieval heredada de siglos anteriores. Aún así Orihuela tuvo ocasión de mostrar sus quejas ante el monarca no sólo a través de las cartas enviadas sino en su representación en Cortes (brazo real). Sirva como ejemplo de dicha intervención regia la limitación del número de ciudadanos con derecho a examinar a los nuevos graduados realizada mediante la provisión real de mediados de mayo de 1459 y la de 1474, por la cual, se cambió la composición de los ciudadanos que debían de supervisar los procesos de graduación. De un primer número de cuarenta personas se pasó a reducirlo a un grupo de dieciséis (en la graduación extraordinaria de mayo de 1459) formado por representantes de los tres estamentos ciudadanos: homens de paratge, ciutadans maiors y ciutadans menors. La representatividad entre los dos primeros grupos fue la misma y en el caso de los ciutadans menors su número fue inferior ${ }^{25}$.

${ }^{23}$ BARRIO BARRIO, J.A., Gobierno municipal en Orihuela..., op. cit. p. 217.

${ }^{24}$ A través de ellas se han podido conocer desde los movimientos del rey según firmaba las cartas en diversas ciudades (Barcelona, Zaragoza o Valencia). Esta corte itinerante era una de sus principales características en la Baja Edad Media.

${ }^{25}$ A.M.O., Contestador, número 32, Carta de 2-junio-1474, fol. 44r. 
El consell de Orihuela se fue doblegando a todo el amplio proceso institucional en toda la Corona de Aragón de uniformidad legislativa auspiciada por el rey. Todo este proceso no exento de situaciones bélicas endémicas comunes como las luchas del patriciado local y por situaciones propias (la situación geográfica en la frontera meridional militar de la Corona de Aragón ${ }^{26}$ ). Los documentos estudiados muestran la vida pública de la nobleza urbana de Orihuela así como su organización, el monopolio del ejercicio del poder municipal y sus luchas entre facciones. Todo ello, puesto de manifiesto en las recusaciones y en las denuncias de fraudes a la hora de resultar graduado para pertenecer a una de las bolsas de ciudadanos (las que daban acceso directo al poder político local) ${ }^{27}$. Pues bien, la ciudad siempre había estado bajo el control de una reducida oligarquía que durante el siglo XIV dominaba el sistema municipal de elección denominado cooptación. El siglo XV fue la implantación del sistema de insaculación, y con ello, la ampliación del número de miembros municipales y de linajes que aspiraban a controlar la vida política. Esta situación generalizada se observaba además en ciudades como Mallorca ${ }^{28}$, Valencia ${ }^{29}$

${ }^{26}$ Sobre cuestiones de esta frontera meridional, véase, CABEZUELO PLIEGO, J.V. y SOLER MILLA, J.L., «Por aquella tierra que está en medio. Violencia y negocio en la frontera meridional valenciana durante el primer tercio del siglo XIV», VI Estudios de Frontera, Población y Poblamiento, Homenaje a don Manuel González Jiménez, Alcalá la Real (Jaén), 2006, pp. 133-150. ORTUÑO MOLINA, J., SOLER MILLA, J. L., «Espacio jurisdiccional y espacio económico en el Sureste Peninsular en la Baja Edad Media», Journal of Medieval Iberian Studies,1:1, Michigan-EE.UU. 2009, pp. 69 -85. SOLER MILLA, J.L. y URZAINQUI, S., Violencia nobiliaria y conflicto jurisdiccional en la frontera sur valenciana durante la Baja Edad Media, Alicante 2010, en prensa.

27 Sobre el estudio de las oligarquías urbanas en la Baja Edad Media, véase, JARA FUENTES, J.L., «Elites urbanas y sistemas concejiles: una propuesta teórico-metodológica para el análisis de los subsistemas de poder en los concejos castellanos en la Baja Edad Media», Hispania, vol. LXI/1, nº 207, Madrid, pp. 221-266. MOLINA MOLINA, A.L., El campo de Murcia en el siglo XV. Murcia. 1989. VALDEÓN BARUQUE, J., «Las oligarquías urbanas», Ciudades y concejos en la Edad Media Hispánica. Ávila, 1990. JIMÉNEZ ALCÁZAR, J.F., «Corregidores y poder municipal: Lorca 1475-1516», 1490: En el umbral de la Modernidad. El Mediterráneo europeo y las ciudades en el tránsito de los siglos XV-XVI, Valencia, 1994, pp. 87-96. REINHARD, W. (coord.), Las elites del poder, la construcción del Estado. Madrid. 1996. JIMÉNEZ ALCÁZAR, J.F., Un concejo de Castilla en la frontera de Granada: Lorca 1460-1521. Granada 1997. CABRERA SÁNCHEZ, M., Nobleza, oligarquía y poder en Córdoba al final de la Edad Media. Córdoba 1998. PÉREZ GARCÍA, M., «Familia, poder y linaje. Conformación de bandos y surgimiento de luchas en torno a la oligarquía murciana (siglos XV-XVI)», VI Estudios de Frontera, Población y Poblamiento, Homenaje a don Manuel González Jiménez, Alcalá la Real (Jaén), 2006, pp. 555-561.

${ }^{28}$ URGELL HERNANDEZ, R., «El municipi de Mallorca en el segle XV», La Ciutat de Mallorca, 750 anys de govern municipal, Mallorca 2000, pp. 29-44.

${ }^{29}$ NARBONA VIZCAÍNO, R., Malhechores, violencia y justicia ciudadana en la Valencia bajomedieval. Valencia, 1990. Ib. (coord.), «Oligarquías políticas y elites económicas en las ciudades bajomedievales (siglos XIV-XVI), Revista d'història medieval, 9, Valencia 1998. 
y Murcia ${ }^{30}$, entre las más cercanas y destacadas en la segunda mitad del siglo XV. Y también complementarias de los estudios realizados sobre Barcelona ${ }^{31}$ uno de los centros urbanos más dinámicos en el ámbito político dentro del reinado de Juan II de Aragón y escenario militar de una guerra civil. Pero estos ejemplos estudiados sobre la vida política municipal en este período se unen a los ya existentes sobre ciudades europeas en el final de la Edad Media. En ellas se distinguían esas características comunes como la sociedad jerarquizada, las luchas de poder ${ }^{32}$, las facciones urbanas, las reclamaciones ciudadanas, los peligros de las fronteras, la agrupación de individuos en colectivos (cofradías y gremios) y los cambios de mentalidad urbana tanto colectiva como individual. En cuanto al poder político urbano se apreciaba esa continuación de la existencia de oligarquías locales que pugnaban por el poder, y que cada vez, contarán con más miembros adeptos en base a la cesión de prebendas aún así defenderán los privilegios antiguos de la ciudad frente a la intromisión de la monarquía. Todo ello, esgrimiendo las ordenanzas locales, los privilegios de siglos y las concesiones reales recibidas desde el siglo de la conquista cristiana.

\section{CONCEPTUALIZACIÓN: ÉLITE, OLIGARQUÍA Y PATRICIADO}

El «linaje», como definía Adelina Rucquoi ${ }^{33}$ : «es la forma específica de asociación de la clase dirigente, y el gremio lo es de los artesanos y mercaderes». La segunda mitad del siglo XV fue una acentuación del agrupamiento de los ciudadanos en torno a puntos de unión ya sean los gremios, las cofradías o las facciones urbanas. Se fue apreciando en la vida pública como el poder ya no era ejercido por un hombre sólo sino que existirán instituciones de control más o menos eficaces, según las épocas, pero es evidente que los privilegios como el de insaculación marcaran la definición de las competencias de los oficios municipales tratando de limitar y controlar su influencia en las decisiones del consell municipal. Este

\footnotetext{
${ }^{30}$ PIQUERAS GARCÍA, B: El concejo de Murcia a fines de la Edad Media (1462-1474). Murcia 1987. JIMÉNEZ ALCÁZAR, J.F., «Los parientes e amigos de los unos e de los otros: los grupos de poder en el reino de Murcia (siglos XIII-XVII)», Anales de la Universidad de Alicante, Historia Medieval, 13, Alicante 2000-2002, pp. 103-156. MOYANO MARTÍNEZ, J.M., «Familia y poder político en la Murcia bajomedieval (siglos XIV y XV)», Miscelánea Medieval Murciana, vol. XVII, Murcia 1992, pp. 11-41.

${ }^{31}$ AMELANG, J., La formación de una clase dirigente: Barcelona, 1490-1714. Barcelona 1986.

32 CHACÓN JIMÉNEZ, F. y HERNÁNDEZ FRANCO, J. (edit.), Familias, poderosos y oligarquías. Murcia 2001. La matización en el concepto que realizan estos dos autores sobre la distinción que se puede hacer de que un poderoso no necesariamente puede corresponderse con un oligarca interesado en el poder sino en controlar las influencias que conllevan ese poder.

33 RUCQUOI, A., Valladolid en la Edad Media: la villa de Esgueva. Valladolid 1983, p. 12.
} 
concepto de consell se irá ampliando a lo largo de siglo XV y pasará de ser concebido como un concejo cerrado en donde el sistema de cooptación había limitado el acceso de los nobles. La modificación y ampliación del sistema de insaculación le dará más sentido de reunión (de comunidad) por la ampliación del número de sus miembros así como la entrada de las bolsas de electos de algunos ciudadanos que anteriormente no tenían derecho a pertenecer a estas bolsas. Había una composición estamental ${ }^{34}$ en la confección de las bolsas desde los que poseían el fuero militar hasta los rentistas agrícolas que no ejercían un oficio mecánico hasta la última bolsa donde estaban esos oficios mecánicos (menestrales).

Como ya se ha citado el tema objeto de este estudio han sido las instituciones políticas en una ciudad bajomedieval del reino de Valencia perteneciente a la Corona de Aragón, y por ello, es imprescindible situar los dos conceptos más utilizados y los que forman el cuerpo del presente trabajo: oligarquía y patriciado. Ambos conceptos se integran dentro de un concepto mayor el de élite urba$\mathrm{n}^{35}$. Hay que entender por élite urbana al conjunto de familias que por su poder económico, su posición social-estamental, su prestigio en función del linaje y las relaciones políticas mantenidas dentro del microespacio de una ciudad valenciana como Orihuela ${ }^{36}$. De este grupo social dependían las decisiones políticas que afectaban a toda la comunidad que vivía en su entorno (ya sea la propia ciudad, su término municipal y las relaciones establecidas con los lugares fronterizos). Ya se ha dicho que uno de los usos de la época y requisito imprescindible para la ocupación de un oficio municipal en muchas ciudades medievales a lo largo del siglo $\mathrm{XV}^{37}$ era la posesión de un caballo y armas. Este requisito aparecía re-

${ }^{34}$ Se distinguían entre: caballeros (generós), ciutadans de ma maior (ciutadans honrrats) y ciutadans de ma menor (gentils hòmens). Definición estamental aportada por BERNABÉ GIL, D., Monarquía y patriciado urbano..., op. cit. p. 33.

35 Desde el punto de vista conceptual sobre la elite urbana como grupo social de poder, véase, ABELLÁN, J., «Historia de los conceptos (Begriffsgeschichte) e historia social. A propósito del diccionario Geschichitliche Grundbegriffe», S. CASTILLO (coord.), La historia social en España: Actualidad y perspectivas, Madrid, 1991, pp. 47-64. SÁNCHEZ LEÓN, P., «Nobleza, Estado y clientelas en el feudalismo. En los límites de la Historia social», S. CASTILLO (coord.), La historia social en España: Actualidad y perspectivas, Madrid, 1991, pp. 197-216. PASTOR, R., SÁNCHEZ LEÓN, P. et alli., «Baja nobleza: aproximación a la historiografía europea y propuestas para una investigación», Historia Social, n. 20, Madrid, otoño 1994, pp. 23-45.

${ }^{36}$ BARRIO BARRIO, J.A., «Las élites urbanas en la gobernación de Orihuela. Los sistemas de creación, acceso y reproducción del grupo dirigente en un territorio fronterizo», Anuario Estudios Medievales, 32/2, Barcelona 2002, pp. 777-808.

${ }^{37}$ Diversos autores coinciden en precisar que en la segunda mitad del siglo XV se fue consolidando el poder de los linajes frente a la Corona. BARRIO BARRIO, J.A., Gobierno municipal en Orihuela..., op. cit.; NARBONA VIZCAÍNO, R., Malhechores, violencia y justicia..., op. cit. y AMELANG, J., La formación de una clase..., op. cit. 
cogido en los capítulos de los privilegios de las ciudades que tenían concedido el sistema de insaculación ${ }^{38}$.

Estas familias establecían su poder y su red de influencias entorno a lazos horizontales de poder entre las distintas políticas matrimoniales que las vinculaban como linajes más extensos (parentesco, amistad y endogamia matrimonial) y los lazos verticales con el rango superior en el poder (otros linajes, oficios superiores o el propio rey). Estos lazos sólo tenían trascendencia política entre estos estamentos privilegiados porque desde ellos se ejercía el poder al conjunto de la comunidad urbana. Algunos de estos linajes dominaron el poder político en Orihuela a lo largo del tiempo como los Maça de Liçana, Rocamora, Rocafull o Masquefa entre los más influyentes pero no en todas las épocas esta jerarquía del poder se mantuvo estable. En ocasiones se producían enfrentamiento armados entre los linajes que daban cuenta de la verdadera realidad de la pugna política que se vivía en el ámbito meridional del reino de Valencia. Estos enfrentamientos nobiliarios ${ }^{39}$ del ámbito valenciano, bien armados o bien en la lucha por la influencia del poder, hacía que estas oligarquías urbanas fueran variables tanto en su número como en su prestigio social ya que podía ser alterado según las coyunturas políticas del momento. Es decir, que el estudio de un período concreto permite conocer las oligarquías del poder, pero no por ello, extrapolar su influencia y prestigio a otras épocas históricas. Aunque el conocimiento del conjunto de las familias/linajes permitirá establecer los apellidos que formaban esta élite urbana ${ }^{40}$.

Existen diversas corrientes historiográficas interesadas en tratar de definir ciertos conceptos propios de cada una de las épocas históricas a las que están

${ }^{38}$ El estudio sobre la implantación y cumplimiento de los capítulos que formaban el conjunto del privilegio de la insaculación en la ciudad de Orihuela es una de las principales bases de la investigación histórica realizada durante el reinado de Juan II de Aragón (1458-1479).

39 Véase, GUINOT, E., «Aprosimació a la noblesa valenciana en la segona meitat del segle XV», XVI Congrés d'Història de la Corona d'Aragó, La Corona d'Aragonesa ai tempi di Alfonso II el Magnanimo, Paparo, Napols, vol. I: pp. 899-913.

${ }^{40}$ Incluso el concepto tan utilizado de élite fue acuñado a principios del siglo XX por la historiografía europea para tratar de definir a la minoría poderosa y dominante en una comunidad humana. Sobre este tema destaca el trabajo de PARETO, W.: Escritos sociológicos. Madrid. 1987. Por ello, estas élites urbanas eran un reducido grupo social que basaba su riqueza en la acumulación de bienes que le permitían ampliar su influencia dentro de la ciudad. Esto les permitía monopolizar el poder político y tener dotes de mando sobre otros linajes lo cual les situaba en el escalafón más alto dentro de su propio grupo estamental privilegiado. Esta situación se podía mantener durante el tiempo independientemente de la variación y composición de sus miembros y las redes establecidas. También es importante precisar que su área de influencia solía ser frecuente que fuera únicamente local abarcando la ciudad y su término ya que otros linajes pugnarían por el control del poder en un ámbito político-administrativo de rango superior. 
dedicadas las investigaciones históricas ${ }^{41}$. En sentido más amplio se ha pretendido vincular el concepto de oligarquía con el de linajes familiares y otros autores definen como élites del poder urbano ${ }^{42}$ o simplemente como élites ${ }^{43}$. Se trata de situar, que dicho concepto más amplio, define a un grupo reducido de familias que por privilegios reales, por pertenencia a los estamentos privilegiados o por la ostentación de los cargos públicos formaban la élite del poder político, económico y social de una ciudad. Entrando aún más de lleno en el análisis del concepto de oligarquías familiares (linajes) se puede concretar que dentro de ellas, se situaría el patriciado urbano, esto es, un número más reducido aún de familias que teniendo las mismas características que las oligarquías, ya que forman parte de ellas, en cada momento histórico ostentaban los principales oficios municipales en las ciudades. Diversos autores ${ }^{44}$ señalan que en la Baja Edad Media, con el desarrollo de las ciudades medievales y la ampliación de sus competencias y jurisdicciones por delegación o por pugna con el rey a través de la concesión de privilegios, fue el momento del origen de la formación de estos grupos de poder ciudadanos. Así se observó en los estudios realizados en esa época en Orihuela, Valencia y Barcelona. El conocimiento de estas élites urbanas es básico para conocer el origen de la consolidación de las instituciones locales como parte de la construcción del Estado ${ }^{45}$. Es decir, el concepto de oligarquías se aplicaría a las familias y linajes que controlaban las diversas clases de poderes ciudadanos y en cambio, el patriciado, se aplicaría al reducido grupo de familias que estaría vinculado a los oficios municipales - los que ejercen el monopolio del poder institucional-.

En la Baja Edad Media fue frecuente la existencia de linajes familiares enfrentados en cada una de las ciudades tanto de la Corona de Castilla como la de Aragón. Fue la lucha por el control de los abastecimientos, la pugna por los privilegios familiares, entre otros motivos los que llevaron, en ocasiones, a luchas armadas. En el reino de Murcia se puede citar como ejemplo la pugna de las familias Dávalos y Fajardo por el control del oficio de Adelantado del rei-

${ }^{41}$ CHACÓN JIMÉNEZ, F., «Historia de grupos: parentescos, familias, clientelas, linajes», S. CASTILLO y R. FERNÁNDEZ (cood.), Historia social y Ciencias Sociales, Lleida, 2001, pp. 165-183. ABELLÁN, J., «Historia de los conceptos..., op. cit. p. 47.

${ }^{42}$ CHACÓN JIMÉNEZ, F., «Historia de grupos..., op. cit. p. 165.

${ }^{43}$ PARETO, W., Escritos..., op. cit. p. 35.

${ }^{44}$ Véase, PARETO, W., Escritos..., op. cit.; MONSALVO ANTÓN, J.M., «Parentesco y sistema concejil. Observaciones sobre funcionalidad política de los linajes urbanos en Castilla y León (silos XIII-XV)», Hispania, LIII, n. 185, Madrid 1993, pp. 937-969. REINHARD, W., Las élites del poder y la construcción del Estado. México 1997. CHACÓN JIMÉNEZ, F: «Historia de grupos... op. cit.

${ }^{45}$ REINHARD, W., Las élites del poder..., op. cit. p. 53. 
$n 0^{46}$. También son significativas las luchas por todo el reino entre los Calvillo y los Ayala ${ }^{47}$. Estas pugnas entre un grupo de reducidas familias darán lugar a la existencia de oligarquías familiares como por ejemplo los Morata en Lorca, los Piñero en Mula, Robles en Caravaca y Carreño en Cehegín. Estas luchas armadas también tuvieron lugar entre las familias ciudadanas y el Adelantado del reino como sucedió con el cerco de Caravaca del año 1461 entre el adelantado Fajardo y los linajes del lugar ${ }^{48}$. Dentro del patriciado urbano era habitual la pugna por el poder extendida por los linajes familiares. Los oficios municipales se heredaban de padres a hijos o de familiares colaterales. Por ejemplo en Murcia estos oficios estaban controlados por las familias: Fajardo, Lisón, Cascales y Puxmarín ${ }^{49}$. En Orihuela existían las mismas pugnas políticas pero con otras familias locales.

\section{EL PROCESO DE GRADUACIÓN PÚBLICA}

\section{(CANDIDATOS ELECTORES). TRES ESTAMENTOS: CABALLEROS Y HÒMENS DE PARATGE, HONRATS CIUTADANS- CIUTADANS DE MÁ MAIOR Y CIUTADANS DE MÁ MENOR}

En el primer momento de la subida al trono de Juan II de Aragón se produjo la primera intervención de la Corona en los asuntos municipales de Orihuela ${ }^{50}$. Posiblemente, el rey, conocedor de los problemas encubiertos en la ciudad por la existencia de facciones y de continuados fraudes en los procesos de inclusión de electores en las bolsas de ciudadanos, decidió el nombramiento de las dieciséis personas (miembros de la oligarquía urbana) encargadas de realizar una nueva graduación en mayo de 1459 a tenor las protestas recibidas de varios ciudadanos de Orihuela que se sentían agraviados por su exclusión de la anterior graduación celebrada en diciembre de 1458. En este sentido, algunos de estos ciudadanos habían informado al rey no sólo de las irregularidades a la hora de aceptar o rechazar a algunos electores sino que además se habían producido fraudes en esas elecciones al aceptar a algunos candidatos que no reunían alguno de los capítulos del privilegio de insaculación vigente en Orihuela. El fraude habitual que era señalado por los agraviados era la posesión del caballo. En algunos casos no se justificaba su posesión, en otros no tenía la edad reglamentaria como mínimo

\footnotetext{
${ }^{46}$ JIMÉNEZ ALCÁZAR, J.F., «Los parientes e amigos de los unos..., op. cit. p. 117.

47 Ibídem, p. 132.

${ }^{48}$ Ibídem, p. 130, 135, 138 y 139.

${ }^{49}$ MOYANO MARTÍNEZ, J.M., «Familia y poder político..., op. cit. pp. 27 y 39.

50 BARRIO BARRIO, J.A., "La intervención real en la ciudad de Orihuela a través de la suspensión de la insaculación en 1450 y su reimplantación en 1459», Pedralbes. Revista d'Història Moderna. Tercer Congrès d'Història Moderna de Catalunya, 13-I, Barcelona 1993, pp. 401-408.
} 
de tres años y en otros su compra se hizo posteriormente a la consecución del derecho a ser electo, y no, antes como era preceptivo para presentar la solicitud a la ciudad.

Sea como fuere no se está señalando que los posibles electores quedaran fuera del proceso de resultar elegidos para algún oficio municipal sino que las acusaciones de fraude se derivaban del hecho de ser excluidos de la principal bolsa de ciudadanos de Orihuela, la correspondiente a la de caballeros y hòmens de paratge, y su inclusión en una bolsa de menor categoría social como la de ciudadanos mayores o de ciudadanos menores. Posteriormente, Juan II de Aragón optará por prestar especial atención a que se cumpliera lo estipulado en el privilegio de insaculación que obligaba a que hubiera una alternancia anual en el cargo de justicia criminal. Cada año debía de alternarse en el principal oficio un miembro de la bolsa de los caballeros y al año siguiente de los ciudadanos mayores. Aún así la pugna de las facciones ciudadanas estaba en mantenerse dentro de la bolsa de los caballeros y optar a ese oficio cada vez que fuera extraído mediante el sistema de azar (redolins).

En consell de 6 de febrero de 1459 las autoridades de Orihuela seguían tratando de ratificar los privilegios que tenían concedidos de reyes anteriores. Se decidió enviar a varios mensajeros para conseguir un documento (loació o nova concesió) por la cual se permitiera que los naturales de Orihuela pudieran seguir realizando el proceso de graduación para elegir a sus candidatos a ocupar los oficios municipales $^{51}$. Ya el 13 de abril de 1459 se había realizado dicha graduación ateniéndose a los capítulos del privilegio todavía en vigor pero se observó un intento de fraude dentro del propio consell. En el último proceso de graduación Pere de Galbe había sido excluido de la bolsa de caballeros y por tanto le tocaba ser inscrito en la bolsa de ciudadanos menores. El consell ordenó el envío de un mensajero a entrevistarse con el rey para que le explicase que Pere de Galbe había prestado buenos servicios a la ciudad y al propio rey, por lo que, le solicitaba que fuera mantenido dentro de la bolsa de caballeros. Se le recordaba al rey que Pere de Galbe había servido como mensajero, justicia criminal y al servicio del rey Alfonso V (frare vostre en lo realme de Nápoles). Se solicitaba que se le volviese a graduar para que volviese a la bolsa de caballeros. A pesar de la evidencia de que Pere de Galbe no reunía el requisito precisado en el privilegio de insaculación, lo cierto es que obtuvo el apoyo del consell local que decidió el envío del mensajero para interceder por é $1^{52}$. Apenas siete días después llegaba a la ciudad la ratificación del privilegio de insaculación por lo que la ciudad enviaba una

\footnotetext{
${ }^{51}$ A.M.O., Contestador, número 29, Consell de 6-febrero-1459, fol. 81r.

52 A.M.O., Consell de 13-abril-1459, fol. 118r.
} 
carta a los mensajeros desplazados a la corte para informarles de esta novedad antes de que se entrevistaran con el rey ${ }^{53}$.

Mientras tanto, la existencia de facciones entre la oligarquía de Orihuela era manifiesta en el consell de 22 de abril de 1459. En ese consell se relataba que a pesar de que el rey acababa de ratificar el privilegio de insaculación de la ciudad algunos vecinos habían ido a la corte a reclamar la modificación o suspensión de dicho privilegio ya que se sentían agreujats por el consell. A ese consell acudieron los tres mensajeros enviados ante el rey (Ramón de Rocafull, Jaume Masquefa y Jaume Rocamora) para informar que habían defendido ante el rey los privilegios de la ciudad por lo que la dita majestad lo volgues confirmat ${ }^{54}$. El origen de las reclamaciones del grupo de vecinos disconformes se detallaba algo más adelante en las actas del consell. En ellas se especificaba que diversos vecinos que habían sido incluidos en la bolsa de ciudadanos menores se sentían agraviados con otros que habían sido promocionados de esa misma bolsa y ascendidos a la bolsa de ciudadanos mayores. El consell ordenó que este tema fuera estudiado por Ferrán Silvestre y Anthoni de Galbe. Este último era un familiar directo de Pere de Galbe que estaba siendo beneficiado por el propio consell. Este hecho fraudulento también había sido protestado por los agraviados ${ }^{55}$. Ante la gravedad y el cariz que tomó la protesta el propio consell rectificó con los agraviados y se decidió que fuesen de nuevo graduados para que se les incluyera en la bolsa que correspondiera (sien de nou tornats agraduhat e examinat). En ese mismo consell se informaba a los asistentes que el ciudadano Nicolás Orumbella había recurrido al llochtinent de governador (noble don Pere de Rocafull) por haber sido excluido del proceso de graduación celebrado en diciembre de 1458 (festa de pascua de pentecostés) y que había obtenido una carta del rey en la que se ordenaba a la ciudad que fuera de nuevo graduado ${ }^{56}$. La complejidad de los hechos sucedidos

53 A.M.O., Carta de 20-abril-1459, fol. 118r.

${ }^{54}$ A.M.O., Consell de 22-abril-1459, fol. 122r.

${ }_{55}$ El consell nombró a Antoni de Galbe y a Ferrán Silvestre para que estudiasen las reclamaciones presentadas por varios ciudadanos del estamento de má menor que no habían sido graduados en diciembre de 1458: "Item lo dit magnifich consell attes que algunes qui son en lo sach menor de la agraduacio feta en los meses pasats se tenen mol per agreujats que ara de nou no sien agraduats pertenents que la dita agraduacio lavors feta fon molt perjudicial e que altres que son en lodit sach de lavors se son promoguts $a b$ ab honest e virtuos viure per co ordena que los dits officials ab algunes dels consellers demanant e appellant hi los dits magnifichs mosen anthoni de galbe e en francesc silvestre se justen e veren quines o quals persones ab raho se ven os por veure sien stades agreujades en la dita agraduacio o per merits e virtuos se son disposits e de aquelles ne sia feta relacio en lo consell per co que puxa ordenar ques donar par e acabar repos a la dita ciutat e singulares de aquella dita majestad sia suplicada per la dita ciutat aquells sien de nou tornats agraduhar e examinar.». A.M.O., Consell de 22-abril-1459, fol. 123r.

56 A.M.O., Consell de 22-abril-1459, fol. 124r. 
en la graduación de 1458 quedaba más de manifiesto al informar al consell que los ciudadanos Pere de Rocafull y Jaume Ferri habían acudido a Valencia para obtener alguna provisión real para ser de nuevo graduados. También por su parte, Pere de Galbe y Nicolás Orumbella, informaron al consell de su intención de ir a Valencia para exponer su desacuerdo en la exclusión producida en la misma graduación. Todos tenían que reunir el requisito imprescindible de la posesión de caballo entre otros motivos y lo cual no era cumplido en alguno de los casos (sens frau algu tenia lo dit roci lo qual es propi de el y comprat sens negu frau) ${ }^{57}$. Ese consell de 1 de mayo de 1459 fue presidido por el justicia criminal auxiliado por los jurados y asistieron veintitrés de los cuarenta conselleres con derecho a representación. Ese número de conselleres era suficiente como para legitimar todas las decisiones municipales ya que representaban algo más de la mitad de sus miembros lo que estaba estipulado en los privilegios de la ciudad para que se pudiera celebrar dicho consell.

El proceso de revisión, actualización y realización de la nueva graduación para aquellas personas agraviadas llevó al consell local a confeccionar un conjunto documental que ocupa una parte importante de la documentación contenida en el año $1459^{58}$. El registro de dicha graduación se realizó entre los consells del 1 y del 4 de mayo. En ellos quedaban de manifiesto los motivos de su celebración así como los miembros del consell, los graduadores y los graduados con sus respectivos cambios en las bolsas de ciudadanos (agraduació feta per les sis cavallers e sis ciutadans nomenats per lo serenissim Rey don Juan). En el bando previo realizado antes de la graduación se había permitido la compra de caballo y armas para someterse a su revisión, siempre y cuando, el caballo tuviera un mínimo de tres años de edad como estaba contenido en los privilegios de la ciudad (que per certes persones en lo dit privillegi contengudes sia feta agraduacio de aquella que no sen stats agraduats es volean novament agraduar... comprar cavall e armes per esser agraduats... que han comprat roci o rocins sens algu frau $)^{59}$. El proceso de graduación se inició explicando a los graduadores que para que una persona fuera admitida en la bolsa de insaculados a la que optaba se mantenía vigente el sistema de las habas, es decir, la utilización de dos habas por cada miembro. Una de color blanco y otra de color negro en señal de admisión o de

\footnotetext{
${ }^{57}$ A.M.O., Consell de 22-abril-1459, fol. 125r.

${ }^{58}$ El conjunto documental de la graduación celebrada en mayo de 1459 abarca un total de dieciocho documentos entre rectos y vueltos. Es el mayor registro documental sobre este tema y además es el que ha servido de base para conocer con detalle todo el proceso seguido para la confección de las bolsas de ciudadanos de Orihuela de donde salía el patriciado urbano que controló el poder municipal durante el reinado de Juan II de Aragón.

${ }^{59}$ A.M.O., Consell de 1-mayo-1459, fol. 133r.
} 
rechazo, respectivamente. Por lo cual, se establecía que la persona electa era votada secretamente introduciendo cada graduador una haba del color elegido en una bolsa y finalizada la participación de los dieciséis miembros las habas eran extraídas y contadas. Para ser admitido bastaba tener mayor número de habas blancas que de negras y se estableció que de haber empate de colores, al ser el número de graduadores pares, que hubiera preeminencia de las habas blancas, esto es, que en caso de empate fuera admitido. Así el nombre del admitido era incluido en la bolsa por la cual se presentaba. Tras la explicación a los graduadores del proceso de selección se procedió ante el consell de la extracción de las cajas y de la apertura de los cuatro paños de llaves, es decir, dos paños de la caja exterior que, a su vez, contenía la caja interior también con dos paños y con su apertura se extraía la bolsa de insaculados correspondiente a cada estamento: bolsa de caballeros y hòmens de paratge, bolsa de ciudadanos mayores y bolsa de ciudadanos menores (los quatre panys es dos de la caxa interior e dos de la caxa exterior $)^{60}$.

Así se inició una exhaustiva revisión del proceso electoral municipal comenzando por el recuento de los nombres de las personas inscritas en los redolines que contenían cada una de las cajas, que a su vez, custodiaban las bolsas de ciudadanos y tras su apertura por la comisión de graduados nombrada por el propio rey era presentada y leída ante los miembros del consell. Una vez realizado esa revisión se procedía a extraer aquellos redolines pertenecientes a las personas fallecidas y a actualizar cada una de las bolsas. Es significativo el hecho de que todas las bolsas de ciudadanos contenían un buen número de personas fallecidas pero aún así desde hacía varios años, y en este caso varias graduaciones anuales, los miembros del consell no habían procedido a realizar esta actualización y habían mantenido dentro de las bolsas a los fallecidos con lo cual la posibilidad de ocupar alguno de los oficios municipales era mayor dado la reducción de los miembros efectivos para ocupar dichos oficios. En la revisión de mayo de $1459^{61}$ de las tres bolsas de Orihuela se constataba la dejadez y la connivencia fraudulenta de los sucesivos consells locales al encontrar personas insaculadas ya fallecidas que no habían sido retiradas de dichas bolsas. La bolsa de caballeros contenía cuarenta y dos insaculados de los cuales veintinueve estaban vivos y trece muertos. De la de ciutadans de má major de cincuenta y tres insaculados había treinta y ocho vivos y quince muertos. Y de la de ciutadans de má menor de los sesenta y seis miembros había cincuenta y

\footnotetext{
${ }^{60}$ A.M.O., Consell de 1-mayo-1459, fol. 133v.

${ }^{61}$ A.M.O., Consell de 1-mayo-1459, fols. 133r.-134v.
} 
siete vivos y quince fallecidos ${ }^{62}$. Las cifras oscilaban entre un tercio de fallecidos en la de caballeros hasta aproximadamente un cuarto en la de las otras dos bolsas. El estar insaculado y pertenecer a alguna de las bolsas era un derecho de carácter vitalicio de ahí que se mantuvieran hasta su fallecimiento, pero en esa revisión, se observaba que no había habido una fiscalización anual en cada proceso de graduación de los miembros de cada bolsa. Estos hechos indicaban la dejadez del consell local o los intereses de las facciones por reducir las posibilidades de ser electo anualmente. En la siguiente bolsa de ciudadanos mayores (fon tret lo sach intitulat dels ciutadans majors) fueron también reconocidos los redolines uno a uno y de los cincuenta y cuatro nombres de personas insaculadas se reconoció que había un total de quince nombres de personas fallecidas y se procedió a su extracción ${ }^{63}$. De nuevo, esta bolsa de insaculados presentaba irregularidades como la bolsa de los caballeros.

A pesar de la repetición de dicha graduación lo cierto fue que la primera graduación pública que tuvo lugar tras la aplicación del privilegio de insaculación de abril de 1459 fue la realizada en marzo de $1460^{64}$. Siguiendo lo dispuesto en el capítulo catorce de dicho privilegio se establecía que el segundo miércoles de la fiesta de la Cuaresma tuviera lugar la celebración de la graduación pública para la admisión de candidatos en las distintas bolsas de ciudadanos. El consell del día 5 de marzo de 1460 recogía la realización de un listado de candidatos durante los tres primeros días de la Cuaresma. En total fueron cuatro los candidatos que se presentaron al consell presidido por el justicia criminal y los jurados. Estos candidatos eran: Antoni Amer, Antoni Canall, Fernando Quesada y Marco de Vilafranca. Desde los inicios de la aplicación del sistema de insaculación, y por consiguiente, de la confección de las bolsas de ciudadanos no ha quedado constancia en todos los años del número concreto de redolines que tenían escritos los nombres de las personas que tenían el derecho a ser elegidos en los principales oficios del consell. Sólo en algunos años se mencionaba su número como en el inicio de la extracción del año 1473. Ese año en la bolsa de caballeros y hòmens de paratge había un total de dieciocho redolines ${ }^{65}$. Ese mismo número había también en la bolsa de ciudadanos mayores y de donde fue extraía la persona que ese año ejercería el oficio de justicia civil ${ }^{66}$.

\footnotetext{
${ }^{62}$ BERNABÉ GIL, D., Monarquía y patriciado urbano..., op. cit., p. 209, nota 52.

${ }^{63}$ A.M.O., Consell de 1-mayo-1459, fol. 134v.

${ }^{64}$ En diciembre de 1458 se hizo una graduación en base al privilegio concedido por Alfonso V y en mayo de 1459 tuvo que repetirse una graduación extraordinaria para los numerosos agraviados que presentaron denuncias ante el rey por los fraudes observados en las exclusiones de la de diciembre de 1458.

${ }^{65}$ A.M.O., Consell de 21-diciembre-1473, fol. 4v.

${ }^{66}$ A.M.O., Consell de 21-diciembre-1473, fol. 5r.-5v.
} 


\section{LOS CARGOS ELECTOS: CAUSAS DE NO ADMISIÓN O DE RECUSACIÓN. LA IMPUGNACIÓN DE LOS AGRAVIADOS}

Todos los años durante el proceso de extracción de cargos eran continuas las referencias a la no admisión o recusación de diversas personas para ocupar ciertos cargos a pesar de haber sido ya electos. Las denuncias que constan de algunas personas venían realizadas por otros oficios ya electos y quedaban recogidas en las actas del consell local. No se ha podido determinar con exactitud si la investigación sobre la legalidad de la elección de cada cargo correspondía a una competencia del consell o si más bien las rivalidades entre las facciones de la oligarquía local pretendían obtener un mayor cupo de representatividad mostrando públicamente los motivos de las recusaciones. Este tipo de situaciones no eran esporádicas y en el mismo consell de la elección de oficios ya aparecían los motivos de la no admisión de algunos candidatos elegidos o incluso en el consell siguiente donde se procedía al proceso del juramento de cada uno de los cargos era donde también se señalaba a los que no podía realizar dicho juramento por haber sido recusados. En la mayoría de los casos no se trataba de recusaciones permanentes sino solamente mientras durara la contingencia que lo había originado. Los motivos para la no admisión venían recogidos en los diversos capítulos del privilegio de insaculación. Los más frecuentes consignados en las actas de consell eran:

1. Ser deudor del consell en los impuestos locales aunque no solía especificarse ninguno en concreto. El solo hecho de deber dinero al consell era motivo suficiente de exclusión por lo menos hasta que fuera subsanada la deuda (no fon admes... son deutors al consell).

2. Ser arrendador de alguna de las imposiciones económicas locales (no puguen essser admesos es arrendador en lo any present de la imposició de la ciutat).

3. Por no poder demostrar la tenencia de un caballo a pesar de ser el principal requisito, y no único, para ser incluido en las distintas bolsas de ciudadanos insaculados (lo qual per no tenir rocí no fon admes).

Algunos de estos motivos de exclusión alegados no eran bien recibidos por los afectados y en otros casos el propio consell no tenía demasiado claro los límites de los capítulos reseñados en los privilegios, especialmente, en los primeros años de su aplicación (años 1459 y 1460). Es frecuente encontrar el comentario del consell en el que se aplicaba la exclusión de un cargo electo en base a la interpretación realizada en algún capítulo concreto (no poguen e per admesos... e la interpretació e capitols... sta consultada la dita largament). En ocasiones se mencionaban los continuos debates para llegar a un acuerdo de consenso entre los dis- 
tintos miembros del consell ${ }^{67}$. El motivo que generó la mayor causa de exclusión entre los distintos oficios electos en las tres bolsas de ciudadanos, especialmente en las de ciudadanos mayores y menores, fue la no posesión de un caballo. Es más, éste además era el motivo principal del fraude electoral entre las personas que pretendían ser incluidas en las distintas bolsas de ciudadanos. Sirvan tres ejemplos para ilustrar las continuas exclusiones de cargos electos, algunos de ellos, eran claros signos de intentos de fraude:

1. Los casos de Jaume Rocamora y de Lope Soler en la elección del año 1459. No pudieron acceder al oficio de conselleres por su situación de deudores a la ciudad. Lope Soler pidió la palabra en el consell (27 diciembre de 1459) alegando que no debía ninguna cantidad económica a las arcas municipales por lo que solicitaba poder hacer el juramento para acceder al oficio. El consell saliente se mantuvo firme no permitiendo su juramento y excluyéndole ese año (no fon admes ${ }^{68}$ ).

2. El caso de Vidal Alamanya que fue reconocido como uno de los arrendadores de las imposiciones locales en Orihuela en el año 1459. Ese mismo año se repitió el caso con Johan Roiz, ambos alegaban que aunque fueran arrendadores, no tenían ninguna deuda pendiente con la ciudad. Por su parte el consell solicitó consulta económica de la relación de deudores y sus nombres aparecían allí inscritos. El debate prosiguió hasta que el consell decidió hacerle la consulta al propio Juan II de Aragón. Se aprovechaba la mensajería que debía de realizar Jaime Fernández de Mesa que iba a Barcelona para asuntos propios para trasladarle la consulta el rey (Barcelona en la qual es la data majestad e que sens salari algú) ${ }^{69}$. Este es un ejemplo más de las dudas en la interpretación de los capítulos del privilegio.

3. La no demostración de la tenencia de un caballo era uno de los principales motivos de exclusión o posiblemente el más frecuente en esta época. Además era señalado como uno de los requisitos que mayor control exigía el consell de Orihuela. En este requisito se centraban los mayores fraudes electorales. Su superación suponía la inclusión en una de las bolsas de insaculados de la ciudad. Por ejemplo: el conseller Jaume Fernández no accedió al oficio en el año 1459 al no ser admitido por no tener caballo (per no tenir rocí). En otros casos como la elección de jurados y sobrecequier del año 1460 el consell especificaba que sobre

\footnotetext{
${ }^{67}$ A.M.O., Consell de 21-diciembre-1459, fol. 9r.

${ }^{68}$ A.M.O., Consell de 27-diciembre-1459, fol. 12v. bis.

${ }^{69}$ A.M.O., Consell 27-diciembre-1459, fol. 13r.
} 
las personas electas se debía de comprobar aquellas que poseían caballo y las que habían registrado su caballo en el libro denominado como «Lo Manifest dels Rocins $»^{70}$.

Desde la primera impugnación de algunos agraviados del año 1459, donde volvió a aplicarse el privilegio real para la elección de los oficios municipales, ya aparecieron de nuevo las impugnaciones a la elección de determinadas personas. Posiblemente una parte importante del problema y del enfrentamiento entre los diversos oficios públicos venía derivado por el hecho de que el consell saliente no aplicara el privilegio antes de la elección, es decir, que aunque tras el acto de la graduación y la formación de las bolsas de ciudadanos electos, lo cierto era que hasta el momento de la elección podían sucederse diversas circunstancias que alteraban la situación personal de cada candidato y produciéndose de esta manera las evidentes impugnaciones. Había candidatos que se convertían en deudores del consell local, otros eran arrendadores de alguno de los impuestos, también estaban aquellos que vendían o perdían el caballo por diversos motivos, entre otras cuestiones más que se planteaban. Es decir, que habría sido necesario actualizar previamente los datos de cada candidato con el fin de evitar los sucesos que se protagonizaron tras la extracción y elección de los oficios.

Sea como fuere muchos de los ciudadanos que componían las bolsas incumplían los privilegios e incurrían en incompatibilidades en el caso de salir electos. La variedad de incompatibilidades era extensa según se ha documentado en cada una de las extracciones anuales. Tras realizarse la elección comenzaban las comprobaciones sobre éstas compatibilidades en base a la aplicación de los capítulos del privilegio. Aquí comenzaban los procesos de aportación de pruebas de algunos de los electos para poder realizar el juramento que le daba acceso al oficio. Los electos intentaban siempre ser admitidos para los oficios y el consell suspendía su juramento para no hacer efectivo el uso del oficio asignado. Había un cruce de alegaciones y acusaciones entre distintos miembros de los consells tanto salientes como entrantes. Un primer ejemplo de lo habitual de estos hechos aparecía en la primera extracción del año 1459. La falta de dominio y conocimiento de las interpretaciones de los diversos capítulos del privilegio dieron lugar a la sucesiva consulta directa al rey Juan II de Aragón. Las cartas de la ciudad dirigidas al rey se sucedieron no sólo a lo largo de los años sino también durante meses siempre consultando las posibles interpretaciones y reinterpretaciones de los capítulos que se planteaban en cada elección de cargos. En concreto esto sucedió tras la elección del 27 de diciembre de 1459 con la no admisión de diversos ciudadanos a pesar de haber sido elegidos con las consiguientes impugnaciones.

${ }^{70}$ A.M.O., Contestador, número 31, Consell de 25-mayo-1460, fol. 70v. 
El día 28 el propio consell entrante escribió al rey comunicándole el caso de la no admisión de Jaume Fernández de Mesa. Días después mosén Jaume Rocamora en nombre del rey envió una carta al consell local comunicando su decisión. Jaume Fernández debía de ser admitido en el oficio al que tuvo acceso el día de la extracción. La decisión del rey no debió de ser sencilla ya que en la breve carta se extractaba que se habían realizado averiguaciones tendentes a conocer las declaraciones de unos y de otros tras la solicitud de información por escrito y a la consulta con los oficiales reales. Toda esta situación de impugnaciones sucedía justo un día después de la primera elección ${ }^{71}$.

Otra de las impugnaciones fue resuelta, de nuevo, por intermediación del rey Juan II en una carta dirigida al consell local y fechada el 5 de febrero de 1460. En ellas se citaba la elección de mosén Jaume Rocamora y su recusación por parte del consell. No quedaba en la carta especificado el motivo de tal recusación pero sí se sabía que dicha denuncia había sido presentada por el procurador fiscal del rey en Orihuela. La decisión del rey fue ordenar al consell la admisión del candidato para el cargo electo. En este caso era para conseller (no es ni deu esser impedir en la dita electio). La carta del rey está fechada el 14 de enero por lo que debió de enviarse conjuntamente con todas las impugnaciones producidas en la última extracción desde diciembre de $1459^{72}$. El consell tras la lectura pública de la carta del rey no registró ninguna intervención de ningún cargo municipal sino que se limitó a acatar la orden del rey admitiendo como conseller al afectado por la impugnación que pasaría a realizar el acto del juramento de la toma de posesión (sea admes... de office de conselleria e aja... lo jurament acostumat). Otra vez una carta del rey leída el lunes día 25 de febrero de ese año de 1460 se ordenaba la admisión como conseller de Lope de Soler que también había sido recusado mediante la impugnación de su elección (tampoco consta el motivo que produjo dicha recusación $)^{73}$.

\section{LAS MODALIDADES DEL FRAUDE}

Hay que dejar constancia de la existencia de un fraude continuado en todo este sistema denominado de insaculación. Desde la configuración de las bolsas de ciudadanos hasta la formación de oligarquías familiares o de facciones de clientelismo que se perpetuaron durante años. La realidad del fraude y la no equivocación en la elección se distingue por los motivos de la recusación de muchos de los oficios municipales nombrados cada año. Estos cargos seguramente eran

\footnotetext{
${ }^{71}$ A.M.O., Consell de 27-diciembre-1459, fol. 15r.

72 A.M.O., Consell de 5-febrero-1460, fol. 27r.-27v.

${ }^{73}$ A.M.O., Consell de 25-febrero-1460, fol. 31r.
} 
conocedores de la irregularidad o ilegalidad de su designación pero aún así trataban de acceder al oficio ejerciéndolo a través del juramento hasta ser denunciados. Las denuncias eran continuas en cada año. No se puede determinar si su publicación en las actas de consell trataba de corregir los defectos del sistema o si más bien obedecía a los intereses de aumentar el cupo de la otra facción rival. Sea como fuere las noticias sobre continuos fraudes electorales acompañaban la elección de cualquier cargo anual.

En la reunión del día 27 de diciembre de 1459 se recordaba a los cargos que los capítulos del privilegio eran bastante concluyentes y que era requisito imprescindible para ser admitido poseer un caballo al menos un año antes de la elección y extracción de los oficios y que además el caballo tuviera al menos tres años de edad ${ }^{74}$ (que lo dit rocí lo dia de la manifestació hauria admes tres anys e tenirlo hun any ans). Aún así el intento de fraude se producía y las modalidades de interpretar los capítulos del privilegio de insaculación eran diversas. Así en ese año de 1459 el consell elevó la consulta al rey sobre si alguna persona podía ser admitida si presentaba un potro que en el año de la manifestación cumpliera los tres años. El capítulo treinta y dos del privilegio especificaba en diversos apartados las modalidades de fraude con las que se verían los consells de Orihuela en las extracciones de los oficios anuales. La primera elección de diciembre de 1459 recogía el reflejo habitual en los actos de graduación. Las actas comentaban que algunos graduados compraban un caballo mayor de tres años poco antes de celebrarse el acto de la graduación y de esta forma conseguían introducirse en alguna de las bolsas de ciudadanos. Una vez inscritos en la bolsa durante ese año vendían el caballo y/o compraban un potro menor de tres años. El consell reconocía la ilegalidad del proceso y recordaba en el consell del día 27 de diciembre la obligatoriedad de cumplir los capítulos del privilegio sobre este tema en concreto.

Las pruebas de fraude continuado en el proceso de entrada en las bolsas de ciudadanos a través de la muestra o graduación en donde los vecinos debían de justificar la posesión de caballo y armas fue el momento clave en el cual se producía el fraude masivo. Así se ha observado durante varios años incluyendo los años próximos a la concesión del privilegio de insaculación del año 1459. En las extracciones de diciembre de 1462 se mencionaba expresamente en las actas del consell una nueva modificación que debía de hacerse en el acto de la mostral muestra porque se habían cometido irregularidades en la aceptación de vecinos. El consell local señalaba el fraude en el manifiesto de los rocines en donde constaban personas graduadas, que al ser electas, se comprobaba que no tenían

${ }^{74}$ A.M.O., Consell de 27-diciembre-1459, fol. 14v. 
caballo ni armas. Las autoridades ordenaron que al año siguiente de 1463 en la celebración de la muestra en la que debían de ser presentados los caballos, éstos debían de ser presentados acompañados de sus legítimos dueños o con otras personas delegadas pero que solo fueran inscritas en dicho manifiesto de rocins los que únicamente tuvieran caballo y armas y cuya certeza no ofreciera lugar a dudas. Y además se ordenaba que en esta misma muestra en vez de ser celebrada anualmente como marcaban los privilegios que se hiciera a partir de ahora tres veces al año. Esto es: la primera el domingo antes de la fiesta de la Pascua de Pentecostés, la segunda el domingo antes de la fiesta de san Miguel y la tercera el domingo antes de la fiesta de Navidad ${ }^{75}$. No se cita en ese momento que dicha modificación solo podría ser efectuada por el propio rey mediante la concesión de una provisión real pero en el consell de 24 de enero se realizó el pago a varios mensajeros, entre ellos a Jaume Masquefa (cavaller), que había regresado de varios cometidos hechos por la ciudad ante el rey Juan II aunque no consta cuales fueron los motivos tratados ${ }^{76}$. Posiblemente uno de ellos fue ver al rey para negociar dicha modificación en los actos de los manifiestos de rocines de Orihuela.

El propio consell de Orihuela a instancia de parte reclamó de Juan II que corrigiera el capítulo catorce del privilegio de insaculación de 1459 en donde se estaban produciendo las denuncias y los fraudes en los procesos de graduación. Esa modificación cambio el número de personas del consell con derecho a realizar la revisión de los candidatos. Juan II estableció y ordenó que desde el año 1460 y en adelante las graduaciones que se realizasen ya llevasen la reducción de conselleres con este derecho (e com la majestad del Senyor Rey per sa provissió a supplicacio de la dita ciutat milloran lo quatorzen capitol tractant de la dita agraduació o promoció $)^{77}$. Para tratar de mantener el orden y la legitimidad en todo el proceso estableció que fueran un total de seis conselleres pertenecientes a la bolsa de caballeros, otros seis pertenecientes a los ciudadanos mayores y cuatro del grupo de los ciudadanos menores ${ }^{78}$. El procedimiento de extracción seguía manteniendo el formulismo del sistema de insaculación designando para las extracciones a un niño menor de diez años y el cuenco de agua en donde flotaban las cédulas que contenían los pergaminos.

Ante las continuas denuncias de fraudes e irregularidades en la confección de las bolsas de ciudadanos el consell de la ciudad de Orihuela había solicitado del rey la concesión de una provisión real en la cual se modificase el número de conselleres con derecho a participar en las graduaciones y en las promociones de

\footnotetext{
75 A.M.O., Contestador, número 22, Consell de 27-diciembre-1462, fols. 247r.- 247v.

${ }^{76}$ A.M.O., Consell de 24-enero-1462, fol. 248.

77 A.M.O., Consell de 10-marzo-1462, fol. 252r.

${ }^{78}$ A.M.O., Consell de 10-marzo-1462, fol. 252v.
} 
ciudadanos. En consell de 19 de marzo de 1462 se realizó la nueva graduación para revisar las bolsas de ciudadanos con derecho a ser electos en los procesos anuales de extracción de oficios. Esta revisión de las bolsas no sólo incluía la aceptación o no de los candidatos sino además la promoción a otras bolsas de ciudadanos (segon dimecres e la cuaresma... feta agraduació... agraduar e promoure) ${ }^{79}$. El proceso que se siguió fue el que estaba registrado en el capítulo catorce del privilegio de insaculación (juxta forma del quatorzen capitol del privilletgi appellat del sach o regiment). Fueron abiertas las bolsas de caballeros, de ciudadanos mayores y de ciudadanos menores. Tras ese proceso habitual fue realizado el proceso de selección de candidatos ${ }^{80}$. Los graduadores encargados de este proceso fueron los seis de la bolsa de caballeros: Ferrán Soler Bargalló, Manuel Martí, Arnau Rosell, Jaume Masquefa, Pere Gómez y Pere Masquefa ${ }^{81}$. Los seis de la de ciudadanos mayores: Joan Talavera, Manuel Alvarez, Antoni de Vilafranca, Joan García Javaloyes, Guillén Prats y Pere Avella ${ }^{82}$. Y los cuatro de la de ciudadanos menores: Ferrando de Quesada, Daniel de Reig, Daniel Rodrigo y Ferrando Ferri ${ }^{83}$.

Para la entrada en la bolsa de caballeros se presentaron dos candidatos (Pere Ximenez menor y Joan Monsí de Castanyeda). Ambos fueron admitidos mediante el sistema de introducción de las dieciséis habas blancas y negras distribuidas entre los graduadores. Éstos colocaban la blanca si lo aceptaba o la negra si no lo aceptaban en un capiró que estaba colocado en la pared de la sala del consell y el recuento fue registrado por el escribano (mes faves blanques) ${ }^{84}$. Por su parte, para la bolsa de ciudadanos mayores fueron habilitados: Joan García, Joan Dalvarez y Pere Quexans. Fueron rechazados (mes faves negres): Joan Daledo, Jaume Ferri y Nicolau Rodrigo ${ }^{85}$. También fueron admitidos como nuevos candidatos a la bolsa de ciudadanos mayores: Andreu Miro, Gomez Daroca, Antoni Canall y Perot Perez. De ellos los graduadores admitieron a Gómez Daroqua que pasó a ser miembro de dicha bolsa y su nombre inscrito en una cédula de pergamino (como la del resto de miembros).

\footnotetext{
${ }^{79}$ A.M.O., Consell de 10-marzo-1462, fol. 252r.

${ }^{80}$ Para la bolsa de caballeros se presentaron dos candidatos (Pere Ximenez menor y Joan Monsí de Castanyeda) y para la de ciudadanos mayores (Joan García, Joan Dalcaraz, Benito de Vianueva, Joan Darago, Pere Castany -botiguer-, Nicolás Rodrigo, Bertomeu Despuig, Jaume Ferri - apothecari-, Pere Quexans, Joan Daledo, entre otros.

Para promocionar de bolsa de ciudadanos se presentaron cuatro candidatos (Antoni Canall, Perot Perez -mercader-, Andreu Miro y Gomez Daroqua).

${ }^{81}$ A.M.O., Consell de 10-marzo-1462, fol. 253r.

82 A.M.O., Consell de 10-marzo-1462, fol. 253v.

${ }^{83}$ A.M.O., Consell de 10-marzo-1462, fol. 253v.

${ }^{84}$ A.M.O., Consell de 10-marzo-1462, fol. 253v.

${ }^{85}$ A.M.O., Consell de 10-marzo-1462, fol. 254r.
} 
El proceso de graduación, por el cual se procedía a seleccionar el grupo de ciudadanos con derecho a formar parte de las bolsas de ciudadanos que accederían a las elecciones y extracciones de oficios para componer los órganos de gobierno y gestión de la ciudad de Orihuela, presentó a lo largo de los años varias deficiencias y acumuló diversas denuncias entre los miembros que formaban ese otro grupo de ciudadanos que eran los encargados de examinar qué ciudadanos cumplían con los requisitos para ser seleccionados. Tras varios años de denuncias de irregularidades, fraudes continuados y recusaciones de ciudadanos por no cumplir con alguno de los requisitos previos paras ser graduados el rey tuvo que intervenir a mediados del año 1474 y mediante una provisión nueva cambió la composición de los ciudadanos que debían de supervisar los procesos de graduación. El origen de la provisión había tenido lugar en el propio baile general de Orihuela, que ante las denuncias de fraude, recomendó al consell local que solicitara una modificación al rey mediante una provisión. La carta fue enviada el 2 de junio de 1474 al copero de su majestad (Jaume de Sant Angel) y a Galcerán de Soler. En ella se les informaba que por mediación del baile general se solicitaba la modificación del rey en el proceso de graduación local para la formación de las bolsas de ciudadanos (suplicamos per obtenir de sa senyoria E esta forma per lo sdevenidor de agraduacio de les persones que deven esser agraduades pera obtenir los officis de aquesta ciutat). Una cuestión importante de la carta era que Orihuela solicitaba que al recibo de su provisión el coste de ésta sería abonado en la ciudad de Valencia para su ingreso en las arcas del rey ${ }^{86}$. A finales del año 1474 en el nuevo proceso de extracción y elecciones de ciudadanos ya se observaron las modificaciones realizadas por el rey al primitivo privilegio concedido por él mismo en abril de 1459. Habían transcurrido quince años desde su aplicación y ésta era su primera modificación importante. No hay que pensar que esta modificación subsanaría las irregularidades sino que venía a poner una paz temporal a la serie de bandosidades que se habían producido en la ciudad durante la década de los años 60 (Masquefa, Rocamora y Rocafull). En años sucesivos e incluso en el siguiente reinado se volverán a observar nuevas modificaciones y nuevas denuncias que alertaban de las deficiencias del sistema de elección de las ciudades que tenían asignado el privilegio de insaculación en la Corona de Aragón.

En una reunión de diciembre de 27 de diciembre de 1473 se recordaba de nuevo a los miembros electos del consell que era imprescindible que mantuvie-

\footnotetext{
${ }^{86}$ A.M.O., Carta de 2-junio-1474, fol. 44r.
} 
ran caballo y armas todo el período anual que durase el ejercicio del oficio que desempeñaban (continuament sens frau tindren cavall e armes) ${ }^{87}$. Este recordatorio venía dado por las continuas recusaciones que se producían una vez elegidos al comprobarse que muchos de los oficios nombrados no cumplían este requisito y que en el acto de la graduación, de ese año, habían incurrido en un evidente fraude. También se daba el caso, que una vez realizado el juramento oficial ${ }^{88} \mathrm{de}$ toma de posesión, muchos de los oficios se deshacían de los caballos que les habían servido para ocupar un oficio de modo fraudulento. De ahí que dentro del juramento se les obligara al compromiso de mantenerlo por lo menos un año.

\footnotetext{
${ }^{87}$ A.M.O., Consell de 27-diciembre-1473, fol. 11v.

${ }^{88}$ Hasta que no se realizaba el ritual del juramento en la iglesia de San Salvador de Orihuela no se consideraba que la toma de posesión hubiese sido efectiva.
} 